Hispania Sacra, LIX

119, enero-junio 2007, 293-301, ISSN: 0018-215-X

\title{
DIVERSAS FORMAS QUE ADOPTA LA RELIGIÓN ANDINA. YUXTAPOSICIONES PELIGROSAS
}

\author{
POR \\ LEONTINA ETCHELECU \\ Universidad del Salvador (Buenos Aires, Argentina)
}

\begin{abstract}
RESUMEN
Desde temprano los cronistas y doctrineros llamaban la atención de las autoridades sorprendidos de las similitudes rituales de algunas celebraciones paganas con el culto cristiano. De la observación de tales prácticas aparecen las primeras confusiones que dan lugar a la imbricación intencionada de los rituales seguidos por ambas religiones. Los relatos sobre la asimilación de ritos son numerosos entre los cronistas, y suponen un intento por lograr la participación indígena en el ceremonial cristiano.
\end{abstract}

PALABRAS ClAVE: Religión andina, Cronistas, Doctrineros, Rituales, Nativos.

\begin{abstract}
From early time, chroniclers and doctrinarians used to draw authorities' attention to ritual similarities between certain pagan and Christian celebrations. The first confusions, arisen from the observation of those religious practices, gave origin to the intentionally interwoven rites followed by both religions. There are various chroniclers' stories about rites assimilation, which were supposed to be an attempt to achieve natives' participation within the Christian ceremonial.
\end{abstract}

KEY WoRDS: Andean religion, Chroniclers, Doctrinarians, Rites, Natives.

Recibido/Received 02-03-2006

Aceptado/Accepted 21-05-2006

Al sol se dedicó la fiesta más fastuosa que se realizaba en Cuzco. Se le debía venerar y ofrecer sacrificios para que, en su recorrido por el espacio celeste, no abandonara la tierra, ni a sus hijos y retornara brindando sus bondades. 
Así se convirtió Inti Raymi en la mayor celebración desde el noveno Inca $P a$ chacutec Inca Yupanqui, quien habría gobernado aproximadamente entre 1438 y 1471. Pachacutec, se hizo famoso por su triunfo sobre el pueblo de los Chancas, que venció al convertir unas piedras llamadas pururaucas enviadas por los dioses, en verdaderos soldados que derrotaron fácilmente al numeroso ejército Chanca.

Pachacutec debe disputar con su hermano y con su padre, que habían hui$\mathrm{do}^{1}$, su legitimidad como heredero al trono, pero apoyándose en su victoria «religiosa» consagra el poder que los dioses aparentemente le habían otorgado al convertir las piedras en soldados y augurar su éxito. Así la religión actuaba con fuerza ideológica y cohesionadora con el fin de sostener la estructura del imperio, que estaba atravesando una importante etapa de expansión, que continuarían los hijos del noveno Inca, y en la cual el peso de la religión como elemento homogeneizador de las culturas, fue fundamental para mantener los lazos de reciprocidad pactada y continuar con la campaña de expansión militar.

Para la cosmovisión andina, cada mundo tenía una duración de mil años, al término de los cuales perecía un sol y luego aparecía uno nuevo y se reiniciaba el recuento de los años. El pasaje de tiempo transcurrido entre las dos edades era denominado pachacuti tiempo de destrucción y desolación, pero también de grandes cambios y restauración. Es probable que los incas hayan percibido la época anterior al noveno inca como un pachacuti época de guerras con los pueblos vecinos.

En su estrategia, Pachacutec aprovechó los beneficios de la deidad solar, que hasta ese momento era sólo una más dentro del panteón inca, para erigirse en «hijo» del sol y construir su propia ortodoxia, que lo llevaba a considerarse receptáculo de las fuerzas divinas.

El historiador peruano Franklin Pease afirmaba con certeza que no hubo un culto solar pan-peruano antes de la expansión del estado cuzqueño emprendida por Pachacutec. El sol era considerado creador del grupo social que bajo este soberano organizó el estado incaico siguiendo los principios de la civilización del fundador de la dinastía inca, Manco Capac a quien los cuzqueños le debían el origen sagrado de Cusco. Pachacutec, apoderándose del mito fundacional atribuido a Manco (que lanza dos varas en la tierra sacralizando el lugar), trata de establecer una continuidad entre su persona y el arquetipo mítico de éste, que gozaba de un prestigio religioso que el noveno Inca necesitaba para legitimar su poder laico.

\footnotetext{
${ }^{1}$ El Inca Yupanqui incorporó a su nombre el título de Pachacutec y se hizo nombrar Inca aún en vida de su padre Viracocha Inca y contra su voluntad, porque había designado a su otro hijo para sucederlo. Éste fue muerto por los seguidores del vencedor de los Chancas. De ahí que se lo considere como noveno Inca y el primer soberano histórico. Él se invistió con la borla imperial en vida de su padre en un claro acto de usurpación, aunque fue considerado el gran reformador y auténtico fundador del estado inca. Como elementos de cohesión impuso la lengua Quechua y la religión de culto al Sol.
} 
Pachacutec erigido en nuevo monarca, inicia la reforma religiosa que lo catapulta a su condición de sacerdote-rey, de carácter divino, e inicia la reconstrucción del templo mayor de Cuzco, el Qoricancha como el lugar más sagrado. Por todo esto se lo considera como el iniciador de una nueva forma de vincularse con su Dios, dentro de la estructura del imperio.

La religión actuaba de garante de la estructura imperial basada en la producción de excedentes que elaboraban las múltiples etnias asimiladas. Por eso el culto se transformó en una actividad pública fundamental en la que participaban las deidades, las autoridades y las diferentes comunidades que formaban el imperio; se trataba de homogeneizar culturalmente la multiplicidad étnica a través de la religión.

La necesidad de encontrar una vía rápida para la evangelización de los indígenas, permitió que la deidad solar se «convirtiera» al monoteísmo, variante que convenía a los intereses del cristianismo en su necesidad de equiparar un Dios andino creador con el Dios cristiano ${ }^{2}$. Este acomodamiento pastoral facilitaba, sin duda, la tarea de los evangelizadores que en un principio observaban los cultos andinos permitiendo a los indígenas realizar sus rituales de celebraciones que incluían cantos, danzas, mientras el dogma no fuera cuestionado.

Garcilaso de la Vega, en sus Comentarios Reales hace la defensa del Sol como deidad única y universal «que con su luz y virtud criaba y sustentaba todas las cosas de la tierra». Carolyn Dean $^{3}$ afirma que asimilar el culto de Inti Raymi con el Corpus Christi fue intencional y buscaban, con esto, mitigar las nuevas campañas de extirpación de idolatrías de principios del siglo XVII. De este modo Garcilaso procuraba convencer a los españoles de que existía cierto monoteísmo andino para que no fueran acusados de idólatras por los doctrineros como el Padre José de Acosta, que, en 1590, veía con espanto la similitud de ritos de aquella fiesta (Inti Raymi), como «una manera de comunión diabólica» imitando al Corpus Christit .

Los ritos diabólicos, a que hacía referencia el jesuita Acosta, no eran otros que las antiguas costumbres de sacrificar y de comunión que se hacían en Cuzco, en ocasión de las festividades que proclamaban los solsticios de invierno y de verano.

Aunque las fiestas andinas tenían un lugar fijo y una razón de ser dentro del calendario inca, fue factible la yuxtaposición de fechas gracias a que Corpus

\footnotetext{
${ }^{2}$ Algunos autores confieren esta cualidad de «dios creador» a Viracocha, otro mítico héroe fundacional de la dinastía inca.

${ }^{3}$ Carolyn Dean, Inka bodies and the body of Christ. Corpus Christi in Colonial Cuzco (1999).

${ }^{4}$ Tom Zuidema, «La fiesta del Inca, el Corpus Christi y la imaginación colonial: castigo y sacrificio humano como ritos de comunión, Editor A. Molinié. Celebrando el cuerpo de Dios (1999) p. 208.
} 
Christi se celebra casi al mismo tiempo que el solsticio de junio. O sea que Corpus por su dimensión solar permitió una suerte de paralelismo con la festividad mayor de los Incas, el Inti Raymi, que aumentó la ortodoxia inventada alrededor del culto solar incaico, impelidos, como estaban los españoles, a encontrar algún punto común entre ambas religiones.

La identificación de Dios como luz no era ajena al hombre español que por tradición medieval, estaba acostumbrado a imaginar lo divino en términos luminosos y hacer de la luz «la metáfora primigenia de la realidad espiritual» como decía Umberto Eco 5 .

Este hecho es más notable en una fiesta como Corpus Christi, a la que siempre se le buscó superponer el ceremonial prehispánico, cambiando tan sólo el objeto de culto. La práctica era común en el ámbito de la Iglesia Católica, y recordaba las celebraciones paganas que Roma había cristianizado en el norte de Europa.

Tom Zuidema ${ }^{6}$ considera que Corpus Christi al caer en los meses de siembra, coincide con la época en que los ritos imperiales andinos se ejecutaban para la misma fecha, aunque eran una consecuencia de las fiestas de la cosecha y su almacenaje. Por lo tanto, Corpus no reemplazó simplemente la fiesta del Sol, el Inti Raymi, sino también a todo el período en que se llevaban a cabo dichas fiestas, que abarcaría desde mayo a junio del calendario occidental.

\section{¿Qué es HOY La Fiesta del Sol EN CuZCo?}

Hoy en día la celebración se inicia en el templo del Sol, el Qorikancha, cuando los chaskis pututeros (mensajeros) ingresan en la explanada del templo y anuncian el inicio del Inti Raymi.

Los cantos de las diferentes panacas 7 anuncian la aparición del Inca transportado sobre andas que se dirigirá a la zona central para llevar a cabo la ceremonia. Allí los sacerdotes presentan al principal sacerdote, llamado Willaq Uma cestas llenas de sancu, en forma de panes hechos de maíz para que los bendiga. Luego toma estos panes y los mezcla con la sangre de las llamas sacrificadas, una blanca y otra negra.

El Inca soberano presidía el sacrificio hecho por el sumo sacerdote para abrir el cuerpo del animal y leer en sus entrañas los acontecimientos futuros.

\footnotetext{
${ }^{5}$ Umberto Eco, Arte y Belleza en la Estética Medieval. (1997) p. 62.

${ }^{6}$ Tom ZuIDEMA, Ibidem.

${ }^{7}$ La panaca era formada por toda la descendencia de un monarca, excluyendo al que sucedía en el mando

Hispania Sacra, LIX

119, enero-junio 2007, 293-301, ISSN: 0018-215-X
} 
Las vísceras y grasa de las llamas son entregadas a dos sacerdotes, el primero toma los intestinos para hacer los vaticinios del año, y el segundo sacerdote, con el sebo, hace los augurios observando el humo.

Los vaticinios dados por ambos sacerdotes son interpretados por el Willaq Uma, que los comunica al Inca y le pide que se sirva una porción del alimento sagrado (el sancu). Todos los demás sacerdotes hacen lo propio al igual que los demás miembros del séquito y participantes de la escenificación, ya que las princesas incas ofrecían el pan sagrado y la chicha con la que el Inca iniciaba el brindis al Sol, todo en medio de cantos y danzas y vestimentas muy coloridas. De esta manera se rompe el ayuno que guardaban todos desde hacía tres días como preparación para el Inti Raymi.

Finalmente, el Inca lleno de alegría da su último mensaje invocando a su pueblo para que, bajo el amparo de su padre el Sol, continúe practicando los valores de la cultura del Tawantinsuyu, cuya máxima expresión es la reciprocidad.

\section{¿QuÉ TIENEN EN COMÚN CORPUS CHRISTI E INTI RAYMI?}

Desde temprano los cronistas y doctrineros llamaban la atención de las autoridades sorprendidos de las similitudes rituales de algunas celebraciones paganas con el culto cristiano. A tal punto que hubo quienes abonaron la idea de que a América habían llegado Santo Tomás o San Buenaventura a cristianizar a los indios y que a esto se debían las pretendidas semejanzas rituales.

Hemos visto cómo la hegemonía del dios Sol permitió a Pachacutec Inca Yupanqui adquirir un estatus sagrado que coadyuvó a los fines imperialistas del nuevo estado Inca. El culto solar forma parte del discurso político sobre la unión del Tawantinsuyu, como religión oficial es la pauta que debe guardarse en las relaciones con el Inca.

Según Serge Gruzinski 8 podemos encuadrar la festividad de Corpus Christi como instrumento de la Corona destinado a «territorializar» las prácticas ibéricas, una suerte de importación del espacio público europeo al Nuevo Mundo, respondiendo a los lineamientos dictados por el Concilio de Trento que auguraban el triunfo de la religión católica por encima de cualquier otra.

En este sentido los evangelizadores fueron muy precisos en América, al aplicar un catecismo que tenía como dogma a estrenar, el de la presencia de Cristo en la Eucaristía, un Cristo como «lumen» o fuente luminosa. La equiparación con la deidad solar inca provino de la necesidad de explicar las cualidades del

\footnotetext{
${ }^{8}$ Serge GruZinski, El Corpus Christi de México en tiempos de la Nueva España, en Celebrando el Cuerpo de Dios. (1999), p. 152.
} 
Dios cristiano del que se descendía patrilinealmente igual que los Incas hijos del Sol de Cusco.

Desde su llegada a América, la religión cristiana fue impiadosa a la hora de desplazar a su antecesora andina y de ocupar su lugar social como religión del Estado. Pero debido a que a los españoles les era imposible implantarla desde el inicio de la conquista, no tuvieron alternativa y presenciaron celebraciones andinas en las que encontraron algunos puntos de contacto como los ayunos que solían guardar o los ritos de comunión que el jesuita José de Acosta relataba consternado.

De la observación de tales prácticas aparecen las primeras confusiones que dan lugar a la imbricación intencionada de los rituales seguidos por ambas religiones. Recordemos que, la yuxtaposición de fechas de las celebraciones de ambos calendarios, ayudó también a confundir ceremonias.

Es posible que existiera en la mentalidad andina la idea de que la religión católica como religión oficial del estado, debía acatarse por haber sucedido a la religión del Sol9; los indígenas podían ser cristianos sin mayores inconvenientes en lo que a sus creencias correspondía.

La permisividad y continuidad de rituales del comienzo de la conquista confirieron a los andinos derechos adquiridos sobre bailes, danzas y procesiones paganas que fueron difíciles de extirpar. Pero, a medida que los Concilios Limenses iban dictando los postulados a seguir en cuestiones litúrgicas y pastorales, la persecución se acentuaba y alcanzaba ribetes devastadores sobre la cultura y creencias andinas.

En el período colonial Inti Raymi sufre los vaivenes de la evangelización incorporando las mutaciones propias del proceso de extirpación como por ejemplo, el prohibir hacer el sacrificio ritual de las llamas. Luego de su prohibición y ya en el período colonial medio, la fiesta del Sol fue vista dentro de Corpus Christi como epítome del triunfo de la religión católica sobre la idolatría ${ }^{10}$. No obstante, la festividad cristiana era un despliegue de los bailes y cánticos incas que habían sobrevivido a pesar de estar la población sojuzgada cultural, militar, política y económicamente.

Pero a medida que la extirpación alcanzaba a sus viejas tradiciones, iba borrando espacios ocupados por un aceitado ceremonial que servía de engranaje a esa sociedad andina basada en los lazos de reciprocidad y redistribución. El vaciamiento del ritual garante del pacto, necesitaba ser reemplazado por otra modalidad que asegurara la continuidad de la solidaridad entre sus miembros.

\footnotetext{
${ }^{9}$ Gonzalo Lamana, «Identidad y pertenencia de la nobleza cusqueña en el mundo colonial temprano», Revista andina. La invención del catolicismo andino, siglos XVI-XVII, (1996).

${ }^{10}$ Carolyn Dean, Ibidem. 
Lo que permanecía en Corpus Christi era un sentimiento de pertenencia. En sus danzas y cantos manifiestan y reivindican los lazos de solidaridad que existían en el otrora Imperio Inca, si lo consideramos como una asociación religiosa que funcionaba gracias a un rígido ceremonial. Los incas encontraron en el catolicismo, aquellas «virtudes integradoras» imprescindibles para seguir como sociedad. La religión cristiana vino a ocupar el lugar social de la incaica y, la nobleza indígena decidió adoptarla como práctica «acorde a su estatus de elite» ${ }^{11}$. Por esto no les costó a los incas del Cuzco acomodarse a la situación de la festividad cristiana que sufre una suerte de metamorfosis, donde lo católico es expresado en términos andinos.

En resumen, los miembros de las elites incaicas legitimaban sus lugares de privilegio con los pactos de reciprocidad y redistribución basados en el rígido ceremonial que los caracterizaba. De los beneficios que obtuviera su comunidad dependía la jerarquía del curaca entre sus pares. Los incas prehispánicos ya estaban habituados al uso de las ceremonias como prerrogativa para mejorar posiciones y, a su vez, los españoles no hacían más que aplicar sus propios modos de celebración europea, enfatizados por la Contrarreforma.

\section{CONCLUSIONES}

Puede inferirse de la superposición de fechas festivas de los dos calendarios, de la coincidencia para ambas religiones de un tiempo sagrado, de la participación en el Corpus Christi de figuras tan emblemáticas como la del líder étnico y de la expresión popular manifestada en bailes, cantos, interpretaciones, que estamos en presencia de un desplazamiento simbólico de sus propias creencias hacia nuevos formas de culto, por restricciones de aquéllas.

La transubstanciación excede el marco de la custodia. Toda la ciudad sirve de «corpus» teórico para legitimar un misterio imposible de explicar con palabras. Cuzco se transforma en el lugar de encuentro con Dios por ser su centro, lugar sagrado, concepción que no era ajena al imaginario inca.

La religión cristiana se encargará de armonizar ese grupo humano que comparte el «complejo de la fiesta», dentro de una cosmovisión andina, que en vez de sincretizarse, se yuxtapone, corre paralela al ritual cristiano y no interfiere en el dogma, por el contrario, a juicio de sus protagonistas, lo enriquece.

Con la caída del Imperio Inca, se desmoronó la estructura del Estado y junto a ésta, su aparato religioso. La iglesia del Sumo Sacerdote es la que cae junto

11 Gonzalo LAmANA, «Identidad y pertenencia de la nobleza cusqueña en el mundo colonial temprano», Revista andina. La invención del catolicismo andino, siglos XVI-XVII. 1996, N¹, p. 95. 
con el Inca. Pero paralelo a la iglesia oficial del Estado, siempre hubo una práctica religiosa aldeana, de comunidad. Esta práctica es la que se mantuvo subrepticiamente a lo largo de todos estos siglos, y a pesar de tanta campaña de extirpación. Esta práctica es la que continúa incluso hasta nuestros días. La población ha encontrado, desde siempre como solución, ir de una a la otra sin problemas teológicos ni confesionales.

Esa humanidad resignada y compelida a participar en la procesión, seguía practicando su religión familiar, comunal, en el ámbito privado, donde las divinidades son otras y los sacerdotes son diferentes, y esta es la religión que se ha venido practicando desde el siglo XVI hasta hoy. Por eso no podemos hablar de sincretismos, porque se trata de dos religiones separadas. La «andina», por ser oral, es más dinámica que la católica y por esto ha aceptado innovaciones. Aunque se ajusta a lo predeterminado, carece de reglas, por eso cada ceremonia es distinta a otra. Pero sí hay principios generales sobre los que se sustenta. Por ejemplo, en el rito de la Pachamama, cuando surcan la tierra y derraman sangre de una llama sacrificada, a la vez rezan avemarías «cristianizando» sus ritos.

\section{BIBLIOGRAFÍA}

Rosa María ACosta de ARIAS SchereIBer, Fiestas coloniales urbanas (LimaCusco-Potosí), Lima, Otorongo Producciones 1997.

Alberto Alberigo, Historia de los concilios ecuménicos. Salamanca, Ediciones Sígueme 1999.

Pablo Joseph DE Arriaga, La extirpación de la idolatría en el Pirú (1621). Estudio preliminar y notas de Henrique Urbano. Cusco, Centro de Estudios Regionales Andinos «Bartolomé de Las Casas», 1999.

Bernabé Сово, Historia del Nuevo Mundo (1653), Madrid, Biblioteca de Autores Españoles 1956.

Carolyn Dean, Inka bodies and the body of Christ. Corpus Christi in Colonial Cuzco, Durham: Duke University Press 1999.

Jorge Flores OchoA, El Cuzco. Resistencia y continuidad. Cuzco, Centro de Estudios Andinos Cuzco 1990.

«La Linda» en el Corpus Christi Cuzqueño, Cuzco, Talleres gráficos JL, 2000. Hans Georg GadAmER, La actualidad de lo bello. Buenos Aires, Paidos 1998.

Teresa GISBERT, Iconografía y mitos indígenas en el arte. La Paz, Ed. Gisbert y Cia. 1980.

Teresa GisBERT et al. «El arte del siglo XVII en Perú y Bolivia», Summa Artis. Historia general del arte. Tomos XXVIII y XXIX. Madrid: Espasa Calpe 1999. 
Serge GruZINSKI, «El Corpus Christi de México en tiempos de la Nueva España», Celebrando el Cuerpo de Dios. Antonoinette Molinié, editora. Pontificia Universidad Católica del Perú, 1999.

Scarlett O'Phelan Godoy, Kurakas sin sucesione, Cuzco, Centro de estudios regionales andinos «Bartolomé de Las Casas» 1997.

E. H. Gombrich, Los usos de las imágenes. Estudios sobre la función social del arte y la comunicación visual, México, Fondo de Cultura Económica 2003.

Alexandra Kennedy (ed.), Arte de la Real Audiencia de Quito, siglos XVII -XIX, Madrid, Editorial Nerea 2002.

Miguel Angel LAREDO QuESADA, Las fiestas en la cultura medieval, Barcelona, Randon House Mondadori, Editorial Areté 2004

Gonzalo LAMANA, «Identidad y pertenencia de la nobleza cusqueña en el mundo colonial temprano», Revista andina. La invención del catolicismo andino, siglos XVI-XVII (Centro «Bartolomé de Las Casas»), Cuzco, 1 (1996) 73-106.

Alba Moya y Ruth Moya, Derivas de la interculturalidad. Procesos y desafios en América Latina, Quito, FUNADES 2004.

Franklin PEASE, «En torno al culto solar incaico», Humanidades (Revista de la Pontificia Universidad Católica del Perú, Lima) 1 (1967) 109-141

Curacas, Reciprocidad y Riqueza. Lima, Pontificia Universidad Católica del Perú 1999.

Juan Polo De Ondegardo, Los errores y supersticiones de los indios (1559). (Colección de libros y documentos referentes a la historia del Perú, serie I, Tomo 3) Lima, 1981.

Gabriela Ramos, La venida del Reino. Religión, evangelización y cultura en América, Siglos XVI-XX, Cuzco, Centro «Bartolomé de Las Casas» 1994.

Gabriela SiRACusAno, El poder de los colores. De lo material a lo simbólico en las prácticas culturales andinas. Siglos XVI-XVIII, Buenos Aires, Fondo de Cultura Económica de Argentina 2005.

Susan WeBSTER Verdi, «La presencia indígena en las celebraciones y días festivos», Arte de la Real Audiencia de Quito, siglos XVII-XIX, Madrid, Editorial Nerea, 2002.

Luis Eduardo WuFFARDEN, «La serie del Corpus: Storia, pintura e finzione nel Cusco del secolo XVII», Catálogo: La processione del Corpus Domini nel Cusco. Lima: Fondo Pro Recuperación del Patrimonio Cultural de la Nación 1996.

Tom ZuidemA, «La fiesta del Inca, el Corpus Christi y la imaginación colonial: castigo y sacrificio humano como ritos de comunión», Celebrando el cuerpo de Dios, Editor A. Molinié, Lima, Pontificia Universidad Católica del Perú, 1999. 